\title{
Statistical Technique for Grouping Tropical Timbers into Similar Strength Groups
}

\author{
Mohd Jamil Abdul Wahab \\ Forest Research Institute Malaysia \\ Kepong 52109, Selangor, Malaysia
}

Tel: 60-3-6279-7464Ｅ-mail: mohdjamil@frim.gov.my

\author{
Mohd Zamin Jumaat \\ Faculty of Engineering, University of Malaya \\ Kuala Lumpur 50603, Malaysia \\ Tel: 60-3-7967-5340 E-mail: zamin@um.edu.my \\ Mohamad Omar Mohamad Khaidzir \\ Forest Research Institute Malaysia \\ Kepong 52109, Selangor, Malaysia \\ Tel: 60-3-6279-7464Ｅmail: omarkh@frim.gov.my
}

Received: December 23, 2011

Accepted: January 20, 2012 Published: March 1, 2012

doi:10.5539/mas.v6n3p73

URL: http://dx.doi.org/10.5539/mas.v6n3p73

The research is partly financed by Institute of Research Management and Monitoring, University of Malaya, Kuala Lumpur

\begin{abstract}
This paper focuses on statistical technique for the assessment of grouping tropical timbers into similar strength groups. The Student's t-test was conducted to evaluate whether the values of mean MOE in bending of two timbers are statistically different from each other. A total of 23 Malaysian hardwoods of different strength classes were assessed by comparing MOE value of one timber to the next. The assessment is limited to species of data obtained from at least 40 specimens and from at least 5 trees. However, more species can be added by conducting extra test based on the similar test procedure. The results showed that from 23 timbers evaluated, they fall into 6 different levels, indicating 6 different timber groups of similar MOE. The outcome is almost similar to the previous groupings done through different methods. The grouping will serves as a guideline for converting small size specimens' data into the equivalent structural timber test values.
\end{abstract}

Keywords: Tropical timber, Strength group, CE marking

\section{Introduction}

Anecdotal evidence indicates that the earliest report on the mechanical properties of Malaysian timbers was in 1940 by A.V. Thomas. It was documented in the Malayan Forester, which gave the results of small clear tests on green specimen of some timbers. Since then much more data on strength properties had been collected through assessments of small clear specimens. The compilation of test results for the ultimate stresses of Malaysian timbers is represented in the Timber Trade Leaflet No. 34. It contains strength data of the most popular Malaysian timber species in list form, reporting not only the mean values, but also the number of test and the standard deviation for each mean value (Lee, 1993).

To place the Malaysian hardwood timbers in the European strength classes, mechanical properties such as modulus of rupture (MOR) and modulus of elasticity (MOE) derived from structural size specimen tests must be determined beforehand (EN 338). Thus there are only two means to achieve the goal; one is to conduct the destructive 
structural size timber test, or, the other way is to manipulate the existing data so that it is equivalent to the properties obtained from structural size specimen test. In a reference document of the European Standards for structural size timber testing, a clause mentions briefly on the alternative method of determining bending strength and modulus of elasticity of timber by altering existing small clear specimens' data (EN 384).

Two vital properties to be determined from structural size testing are the characteristic values of bending strength and mean modulus of elasticity, and they are allowed to be adjusted from small size specimen data via conversion factor. However, stated in the document that the conversion factor only applies to timbers of similar group.

Therefore it is crucial to group the Malaysian timbers into similar group assemblage. However, the most important issue to be resolved beforehand is what is the term "similar" referring to? Since the whole assessment is apparently concerning the strength and stiffness of timber, hence the term "similar" should reflects the similarity in term of mechanical properties among timbers. And since the mechanical properties of the structural size specimen are undetermined, the similarity of the mechanical properties should base on the data of small clear specimen test.

Small clear specimens are defined as specimens with no visible deviation over the specimen's length. For tropical timber this is hard to distinguish. In practice, even the grain angle deviation is not easy to determine (Geert, 2010). Thus, for tropical timber, it is practical to assume that the small size specimens are the corresponding small clear specimens.

In addition, there is a need to represent Malaysian timbers in a single strength value that accounted the strength variability among species. For example, the required values are the mean MOR and mean MOE of Dark Red Meranti. However, the existing data recorded the mean MOR and MOE of Seraya (Shorea curtisii), Meranti bukit (Shorea platyclados) and Meranti sengkawang merah (Shorea singkawang) separately (Lee, 1993).

As a matter of fact, the practice in the local timber industry is to describe timbers by their trade names. Furthermore, with more than 3000 species of Malaysian timbers, it is almost impossible to characterize the mechanical properties for each species (Wong, 1982). Thus, a single reliable MOR and MOE values for a timber group is valuable to indicate its' mechanical properties which includes the variation between species. Hence a "timber" is agreeable to be a "group of timber having the same trade name in the market".

Engku (1971) calculated basic stresses for Malaysian hardwoods to represent each timber with a single strength value, and subsequently determined the different grades for structural application. However the calculation of the basic stresses for each particular timber was based on a single species instead of considering all tested species. Furthermore, the values are more likely towards safety stipulation for structural design and are not accurate in depicting the strength distribution of the timbers.

Thus, it is necessary to determine the weighted mean and combined standard deviation of MOR and MOE of the multispecies Malaysian timbers since the values affect the depiction of the strength and influence the ultimate utilisation of the timbers. Assuming that the dispersion of strength data for each species for one timber can be represented in a normal distribution plot, weighted mean and combined SD are eventually represent by the combination of each bell curve (Figure 1). The outcome is a single normal distribution plot that represents all tested species for that particular timber. It should be able to portray the strength dispersion from every original bell curve which is actually the strength data distribution of every specimen from every tested species.

Under the older method of grouping Malaysian timbers into strength groups, only the compressive strength is considered. However, in deciding the position of the timber in the corresponding group, bending strength had also been considered. This method divided timbers into four strength group, A, B, C and D (Burgess 1956). Engku (1972) proposed a more accurate A to D strength grouping of Malaysian timbers based on their basic and grade stresses. This modern approach of strength grouping is more indicative of the actual strength properties of the timbers. Later on, Chu Yue Pun introduced the new strength grouping of Malaysian timbers in his textbook entitled the Timber Design Handbook in 1997 (Chu, 1997). This new grouping system introduced the seven strength group namely S.G.1 to S.G.7. However, the grouping procedure was ambiguous and became a dubious issue in the local timber industry since all the related documents are missing.

This assessment is limited to species of small clear specimen data obtained from at least 40 specimens and from at least 5 trees (EN 384). However, that does not means that the unqualified species shall never be permissible to be converted. It is just a matter of adding more data to the existing small clear specimen records simply by conducting extra test based on the similar test procedure (which was 2" by 2" by 30 " static bending test). For example, mean MOR and MOE of bending of Tembusu were obtained from eleven (11) specimens from two (2) trees (Lee, 1993). In order to accumulate Tembusu into the corresponding similar group, an extra 29 number of specimens from another 3 trees should be tested on bending to fulfill the requirements of "at least 40 specimens from 5 trees". 
These analyses however were restricted to data available in Timber Trade Leaflet No.34 - The Strength Properties of Some Malaysian Timbers (Lee, 1993). Some information is not available most likely because they have not been tested for air-dried specimen (Engku, 1971) or probably the values were recorded in some other documents.

\section{Research Methods}

A report by Hugh Mansfield-Williams (2010) suggested that a statistically robust method should be implemented to determine whether timbers in comparison are similar or not. This is applicable since the mean values of the strength data are available and can be compared. Several studies on timber strength comparison had been conducted using t-test analysis. Kliger (1995) done a study on the quality of timber products from Norway spruce based on the t-test calculation. Another work by Okai (2004) compared the mechanical properties between branchwood and stemwood of selected tropical tree species of Aningeria robusta and Terminalia ivorensis by the similar method.

The method for the t-test analysis can be found in most of the mathematic reference books, but for the purpose of the present report, it will be discussed in brief. Generally, the Student's t-test assesses whether the means of two groups are statistically different from each other.

$$
\begin{gathered}
\frac{\text { signal }}{\text { noise }}=\frac{\text { difference between } \text { group means }}{\text { variability of groups }} \\
\frac{\text { signal }}{\text { noise }}=t-\text { value }
\end{gathered}
$$

The top part of the ratio is just the difference between the two means or averages while the bottom part is a measure of the variability or dispersion of the scores. The specific formula is given below:

$$
t-\text { value }=\frac{\bar{X}_{a}-\bar{X}_{b}}{\sqrt{\frac{\operatorname{var}_{a}}{n_{a}}+\frac{\operatorname{var}_{b}}{n_{b}}}}
$$

Once the t-value is computed, a table of significance is referred to check whether the ratio is large enough to say that the difference between the groups is not likely to have been a chance finding. In most research, the rule of thumb is to set the probability level or sometimes called alpha level at 0.05 . This indicates that five times out of a hundred a statistically significant difference between the means will be found even if there was none. It is also needed to determine the degrees of freedom for the test. In the t-test, the degree of freedom is the sum of the specimens in both groups minus two. Given the alpha level, the degree of freedom, and the t-value, the t-value from the standard table of significance is referred to determine whether the calculated t-value is large enough to be significant. If it is not, then it can be concluded that the means for the two groups is almost the same.

\section{Weighted Mean and Combined SD Calculation}

A basic principle in the Europe's system of timber strength classes is that the strength class can be determined by three main properties: bending strength, modulus of elasticity and density. For the bending strength and the density the 5\%-lower fractile has to be determined and for the modulus of elasticity the mean value (Geert, 2004). Thus, modulus of elasticity in bending for specimens at $15 \%$ moisture content was picked as the comparison property since the mean values are available and because it represents the capability of a material to resist external forces. Furthermore, Alik (2006) showed that a weak correlation was found between small clear and structural size timber in term of modulus of rupture. Thus, strength grouping base on MOR values are not appropriate since the grouping meant to aid structural size timber assessment.

The weighted mean for $\mathrm{N}$ samples of $\mathrm{n}$ number of specimens is defined via the equation:

$$
\bar{x}=\frac{\sum_{i=1}^{N} n_{i} x_{i}}{\sum_{i=1}^{N} n_{i}}
$$

Reverse algebraic approach was applied based on the basic SD formula to combine standard deviations. The combined SD calculation for $\mathrm{N}$ samples of $\mathrm{n}$ number of specimens was based on the principle of SD:

$$
s=\sqrt{\frac{1}{n-1} \sum_{i=1}^{n}\left(\bar{x}-x_{i}\right)^{2}}
$$




$$
\begin{gathered}
s^{2}=\frac{1}{n-1}\left(\sum \bar{x}^{2}-2 \bar{x} \sum x+\sum x^{2}\right) \\
s^{2}=\frac{1}{n(n-1)}\left(n \bar{x} \sum \bar{x}-2 n \bar{x} \sum x+n \sum x^{2}\right)
\end{gathered}
$$

and since:

$$
n \bar{x}=\sum x=\sum \bar{x}
$$

Thus, it can be shown that:

$$
s^{2}=\frac{1}{n(n-1)}\left(n \sum x^{2}-\left(\sum \bar{x}\right)^{2}\right)
$$

This equation will be the combined SD formula for MOE data of the multispecies timbers. But before that, $\sum x^{2}$ for each sample will be determined.

From the same equation:

$$
\sum x^{2}=\frac{1}{n}\left[s^{2} n(n-1)+\left(\sum \bar{x}\right)^{2}\right]
$$

\section{Results and Discussion}

Weighted mean and combined SD calculation for Red Balau (RB)

Based on values in Table 1, using the formula of the weighted mean:

$$
\begin{gathered}
\bar{x}=\frac{\sum_{i=1}^{N} n_{i} x_{i}}{\sum_{i=1}^{N} n_{i}} \\
\bar{x}=\frac{(48)(14800)+(31)(17000)}{48+31} \\
\bar{x}=15663.29 \mathrm{Mpa}
\end{gathered}
$$

Solving for $\sum x^{2}$ of species 1 :

$$
\begin{gathered}
\sum x^{2}=\frac{1}{n}\left[s^{2} n(n-1)+\left(\sum \bar{x}\right)^{2}\right] \\
\sum x^{2}=\frac{1}{48}\left(1880^{2}[48][47]+[(48)(14800)]^{2}\right) \\
\sum x^{2}=1.07 \times 10^{10}
\end{gathered}
$$

Solving for $\sum x^{2}$ of species 2 :

$$
\begin{gathered}
\sum x^{2}=\frac{1}{n}\left[s^{2} n(n-1)+\left(\sum \bar{x}\right)^{2}\right] \\
\sum x^{2}=\frac{1}{31}\left(2660^{2}[31][30]+[(31)(17000)]^{2}\right) \\
\sum x^{2}=9.17 \times 10^{9}
\end{gathered}
$$

Hence, for the combined SD is calculated as:

$$
\begin{gathered}
s^{2}=\frac{1}{n(n-1)}\left(n \sum x^{2}-\left(\sum \bar{x}\right)^{2}\right) \\
s^{2}=\frac{1}{(79)(78)}\left(79\left[1.07 \times 10^{10}+9.17 \times 10^{9}\right]-[(48)(14800)+(31)(17000)]^{2}\right) \\
s=2453.54
\end{gathered}
$$

The complete results for weighted mean and combined SD calculation are presented in Table 2.

T-value calculation for Red Balau (RB) and Merbau 
Based on values in Table 3:

Hence:

$$
\begin{gathered}
t-\text { value }=\frac{\bar{X}_{a}-\bar{X}_{b}}{\sqrt{\frac{\operatorname{var}_{a}}{n_{a}}+\frac{\operatorname{var}_{b}}{n_{b}}}} \\
t-\text { value }=\frac{15663-15400}{\sqrt{\frac{2454^{2}}{79}+\frac{2300^{2}}{42}}} \\
t-\text { value }=0.5849
\end{gathered}
$$

\begin{tabular}{ll}
\hline t-value from calculation & 0.58 \\
alpha level & 0.05 \\
degree of freedom & 119 \\
$\mathrm{t}-$ value from the table of significance & 1.98 \\
\hline
\end{tabular}

\section{$t$-value from calculation $<t$-value from the table of significance}

Therefore, based on the t-value calculated, it can be concluded that Red Balau and Merbau are identical based on their MOE values.

The computations were continued in the same manner for the other timbers to find their respective t-value. For multispecies timbers, weighted mean and combine SD were calculated earlier to obtain the representative MOE and SD values for that particular timber group in order to conduct t-value exercise. The t-test was carried out by comparing one timber to the next, rather than comparing similarity between each species in the pack. Meaning, Red Balau was only compared with Ramin and subsequently with Merbau for the t-values rather than comparing it with every species in the list.

The total results for t-value analysis of the mean MOE of the small clear bending test data is represented in Table 2 below. As discussed previously, the entire analyses were restricted only to data available in Timber Trade Leaflet No.34. Besides, the grouping assessment is limited to data obtained from at least 40 specimens and from at least 5 trees for a single species group. However Bitis and Mempisang are included in this assessment since they lack only a specimen to be 40 specimens.

Referring to the results in Table 2, it appears that the results of the weighted mean MOR of RB, Kedondong, Mempisang and Merpauh by no means are issues since the differences of mean MOR within species of a same timber are around $10 \%$ or less (Lee, 1993). Thus, the calculated weighted mean MOR for these timbers are relevant. As for the MOE for these timbers, even though there are differences in the values between weighted mean and species mean, but the gaps are not significant. Thus, for these species, it can be considered that the weighted means of MOR and MOE and combined standard deviations obtained from the calculations are practical.

The differences of the mean MOR between species of Keledang, DRM and LRM vary from $15 \%$ to $22 \%$. While the differences in mean MOE between species vary from $24 \%$ to $33 \%$. If the differences between weighted values and species values of MOR and MOE for these timbers are calculated, the percentages will be much lower (Lee, 1993). Thus, for multispecies timbers known for large strength variation such as Keledang, DRM and LRM, the results of weighted means of MOR and MOE and combined standard deviations obtained from the calculations are reasonable.

On the whole, significant MOR and MOE differences between calculated weighted mean and species mean only seen for timbers known to have great strength variation between species such as Durian, Keruing, Nyatoh and Meranti groups. As a result, large values of combined standard deviation are observed from these timbers. Major differences in the mean MOR and MOE values is apparently an issue since it can directly affect the design and utilisation of the timber. Perhaps results of lower mean values will not agitate the existing structural design calculation, but results of higher values certainly need justifications.

The Malaysian Standard Code of Practice on structural use of timber (MS 544: 2001) is based on basic stresses which were derived from ultimate values of air-dry specimen tests (Engku, 1971). The current strength grouping of Malaysian timber, refer to as S.G.1 up to S.G.7 grouping, was also developed based on basic stresses derived from ultimate strength values (Chu, 1997). Besides, the previous Malaysian strength grouping known as A to D grouping was also put up based from the same basic stresses (Engku, 1972). For the purpose of deriving these basic 
stresses, the analysis was based on the weakest component of the group (Engku, 1971) and most probably with the consideration of sufficient sampling of at least 5 trees.

For example, the reference values of MOR and MOE for Keruing are $96 \mathrm{Mpa}$ and 17,100 Mpa respectively, based on the ultimate stresses of Dipterocarpus baudii. Likewise, the reference MOR and MOE values for Durian are 74 Mpa and 11700 Mpa respectively, based on Durio oxyleyanus. Similarly, the reference MOR and MOE values for Dark Red Meranti are $77 \mathrm{Mpa}$ and $12100 \mathrm{Mpa}$ respectively, based on ultimate stresses of Shore platyclados (Engku, 1971). Referring to Table 2, it is therefore logical to dictate that the weighted mean MOR and MOE of Keruing, Durian and DRM obtained from the calculation are equivalent to the reference values implemented in the MS 544 document.

One important note is that the calculations only involved air-dry specimens. For a better representation of the timber species strength dispersion, it is recommended that more air-dry specimen tests are conducted and more species is added in the sampling. For example, the timber of group Nyatoh was only represented by 2 species of available air-dry data, Palaquium impressinervium and Palaquium gutta, even though there were 5 species tested in total (Lee, 1993). Furthermore, the untested species can become the crucial data in signifying the strength of Nyatoh since they have lower values of green MOR and MOE compared to the two. The issue of the untested species is the same for WM (Lee, 1993). Thus, weighted mean values of MOR and MOE of Nyatoh and WM do not reflect the true strength within their species variation. Apparently, Nyatoh and WM have the largest values of combined standard deviation for MOR.

The t-test results showed that from 23 timbers evaluated, they fall into 6 different MOE levels, from the highest value in group E1 to the lowest value in group E6. Each group is separated for being unequal through the t-value tests performed. Balau, Merbatu and Cengal are in a similar assemblage in E2. Kapur and the others in E3 are demonstrated to be identical, whereas Bitis having the highest MOE among all was unable to be put in equality with any other and is alone in E1. However, taken as a whole, the arrangement is comparable to the A to D Strength Groups by Burgess (1956) and Engku (1972) which all the above timber were placed in strength group A and B. However the array is not similar for S.G. by Chu (1997) where Kapur and Keruing were placed in much inferior strength groups in S.G.4 and S.G.5 respectively. The possible explanation for this disparity could be due to the different grouping procedure employed by Chu which was not documented appropriately.

It appears that group E4 listed the most timbers compared to the other groups. The arrangement is parallel to A to D Strength Groups (Burgess, 1956; Engku, 1972) which put the timbers in Group B and C except for Red Balau which was placed in Group A. This is as well similar to the SG1 to SG7 grouping which the timbers were categorized in SG4 and SG5, except for Red Balau which was placed in SG3 (Chu, 1997). The placing of Red Balau in Group A by Burgess and Engku is explainable by referring to the applied methods. Burgess put a minimum compressive stress value of 55.2 Mpa for Group A timbers, and Red Balau compressive stress value of the species Shorea ochrophloia surpassed the limit. Likewise, Engku set minimum specifications of Group A timbers based on basic and grade stresses, again Red Balau exceeded (Engku, 1971).

The results assembled four timbers in group E5, covering the much lower MOE values. Again, the similarity was recorded in A to D strength grouping which the timbers were sorted in Group C (Engku, 1972). Besides, the arrangement is the same by Chu (1997) which put the timbers in SG5 and SG6. However, there is a slight difference in A to D grouping by Burgess (1956) whereby Durian was located in Group D. This could possibly implies that during the time of Burgess, only the lower strength of Durian species, Neesia altissima was tested and through time, the much higher strength of Durian species were also included in the data (Lee, 1993). Though, the exact dates for each species was tested could not be determined.

The timber with lowest MOE, Terentang, was observed to be unequal to any of the reviewed timbers. This is most probably because of the very low MOE value of Terentang compared to the others in the list. The similar results were also demonstrated in the older groupings which placed Terentang in the lowest strength group of Group D and SG7 (Burgess, 1956; Engku, 1972; Chu, 1997).

\section{Conclusions}

It is not a final declaration for the grouping similar timber task. Further improvement is applicable to lessen the number of groups by additional t-test analysis on other properties such as bending MOR or density. Perhaps a different statistical analysis method can be performed to better illustrate the similarity of the timbers. Also, more species can be added to their respective groups through extra small clear timber specimen tests to obtain more small clear data. 
However, the results reflects that based on average MOE value, a reliable strength grouping can be established for Malaysian timbers. The pattern of timber strength arrangement through t-test analysis indicates that the outcome is almost similar to the grouping by Burgess (1956) which based on compressive stress and also grouping by Engku (1972) which based on basic and grade stresses. In addition, the pattern is also similar to the listing by Chu (1997) despite the work was being criticized for having dubious procedure (Tan, 2010).

Referring to the above table, it can be justified that timbers in E4: Red Balau, Merpauh, Nyatoh, Ramin, Merbau, White Meranti, Bintangor, Keledang and Mempisang are having similarity based on small clear specimens MOE values. Thus conversion factors developed from any of these timbers are valid for every timber in that particular group. For example, conversion factors developed from structural size tests of Red Balau are applied for every timber in E4, even without its' structural size test data.

\section{References}

Alik, D., \& Badorul, H. A. B. (2006). Strength Performance of Full-size Structural Timber of Dryrobalanops Species of Sarawak, Malaysia. 9th World Conference Timber Engineering, WCTE 2006.

Burgess, H. J. (1956). Strength grouping of Malayan timbers. Malayan Forester, 19(1), 33-36.

Chu, Y. P., et al. (1997). Timber Design Handbook. Forest Research Institute Malaysia, Kepong, Selangor.

EN 338. (2009). Structural timber, Strength classes.

EN 384. (2004). Structural timber, Determination of characteristic values of mechanical properties and density.

Engku Abdul Rahman, C. (1971). Basic and Grade Stresses for Some Malaysian Timbers. Malayan Forester, 34(4), 131-134.

Engku Abdul Rahman, C. (1972). Basic and Grade Stresses for Strength Groups of Malaysian Timbers. Malayan Forester, 35(2), 131-134.

Geert, R., \& van de Kuilen, J. W. (2010). Comparison of methods of strength classification of tropical hardwood timber. Proceedings of the Eleventh World Conference on Timber Engineering, Riva Del Garda, Italy, 20-24.

Mansfield-Williams, H. (2010). Assistance with a route to CE marking for Malaysian structural timber. Report for Forest Research Institute Malaysia Kepong, Malaysia. Report reference TE//F10260. TRADA Technology Ltd.

Kliger, I. R., Perstorper, M., Johansson, G., \& Pellicane, P. J. (1995). Quality of timber products from Norway spruce. Wood Science and Technology, 29(6), 397-410. http://dx.doi.org/10.1007/BF00194198

Lee, Y. H., \& Engku Abdul Rahman, C. (1993). The Strength Properties of Some Malaysian Timbers. Timber Trade Leaflet No.34. Forest Department, Kuala Lumpur. (Reprinted)

MS 544. (2001). Code of practice for structural use of timber: Part 2 - Permissible stress design of solid timber (First revision)

Okai, R., Frimpong-Mensah, K., \& Yeboah, D. (2004). Characterization of strength properties of branchwood and stemwood of some tropical hardwood species. Wood Science and Technology, 38(2), 163-171. http://dx.doi.org/10.1007/s00226-004-0232-x

Tan, Y. E., Mohamad Omar, M. K., Chong, S. Y., \& Mohd Jamil, A. W. (2010). Current strength grouping for structural timbers in Malaysia - its derivation?. Proceedings of the International Symposium on Forestry and Forest Products 2010, The Legend Hotel, Kuala Lumpur, 5-7.

Wong, T. M. (1982). A Dictionary of Malaysian Timbers. Malayan Forest Records No. 30. Forest Department, Kuala Lumpur.

Table 1. Mean MOE, standard deviations and number of specimens of Red Balau species

\begin{tabular}{|l|l|c|c|c|}
\hline Vernacular Name & Species Name & $\begin{array}{c}\text { Mean MOE } \\
(\mathrm{Mpa})\end{array}$ & SD & $\mathrm{n}$ \\
\hline Membatu & Shorea guiso & 14800 & 1880 & 48 \\
Membatu Jantan & Shorea ochrophloia & 17000 & 2660 & 31 \\
\hline
\end{tabular}


Table 2. Weighted means and standard deviations of MOR and MOE of some multispecies Malaysian timbers

\begin{tabular}{|l|ccc|ccc|}
\hline Timber Name & $\begin{array}{c}\text { MOR } \\
\text { (Mpa) }\end{array}$ & $\begin{array}{c}\text { Total } \\
\text { number of } \\
\text { specimen }\end{array}$ & SD $_{\text {MOR }}$ & $\begin{array}{c}\text { MOE } \\
(\text { Mpa })\end{array}$ & $\begin{array}{c}\text { Total } \\
\text { number of } \\
\text { specimen }\end{array}$ & SD $_{\text {MOE }}$ \\
\hline Balau, Red (RB) & 99.61 & 79 & 11.30 & 15663 & 79 & 2454 \\
Durian & 77.87 & 55 & 14.76 & 12271 & 55 & 3002 \\
Kedondong & 81.00 & 52 & 8.87 & 12177 & 52 & 1307 \\
Keledang & 100.91 & 46 & 15.47 & 14065 & 46 & 2497 \\
Keruing & 98.34 & 187 & 17.17 & 17645 & 187 & 3432 \\
Mempisang & 81.15 & 39 & 8.37 & 13923 & 39 & 1610 \\
Meranti, Dark Red (DRM) & 82.72 & 93 & 10.49 & 12845 & 93 & 1619 \\
Meranti, Light Red (LRM) & 70.74 & 91 & 9.65 & 12257 & 91 & 2019 \\
Meranti, White (WM) & 101.19 & 127 & 18.54 & 14808 & 127 & 3401 \\
Merpauh & 102.21 & 98 & 11.32 & 16686 & 98 & 2042 \\
Nyatoh & 113.00 & 50 & 24.72 & 16348 & 50 & 3225 \\
\hline
\end{tabular}

Table 3. Mean MOE, standard deviations and number of specimens of Red Balau and Merbau

\begin{tabular}{|l|c|c|c|}
\hline Timber Name & $\begin{array}{c}\text { Mean MOE } \\
\text { (Mpa) }\end{array}$ & $\mathrm{n}$ & SD \\
\hline Red Balau & 15663 & 79 & 2454 \\
Merbau & 15400 & 42 & 2300 \\
\hline
\end{tabular}

Table 4. Groups of Malaysian timbers having the similar MOE

\begin{tabular}{|c|c|c|c|c|c|c|c|c|c|c|c|}
\hline E1 & & E2 & & E3 & & E4 & & E5 & & E6 & \\
\hline \multirow[t]{9}{*}{ Bitis } & 23800 & Balau & 20100 & Kapur & 18700 & Merpauh & 16686 & DRM & 12845 & Terentang & 7000 \\
\hline & & Merbatu & 19700 & Kempas & 18600 & Nyatoh & 16348 & Durian & 12271 & & \\
\hline & & Cengal & 19600 & Kekatong & 18400 & Ramin & 15900 & $\begin{array}{c}\text { Meranti } \\
\text { Light Red }\end{array}$ & 12257 & & \\
\hline & & & & Tualang & 17800 & Balau Red & 15663 & Kedondong & 12177 & & \\
\hline & & & & Keruing & 17645 & Merbau & 15400 & & & & \\
\hline & & & & & & $\begin{array}{l}\text { Meranti } \\
\text { White }\end{array}$ & 14808 & & & & \\
\hline & & & & & & Bintangor & 14300 & & & & \\
\hline & & & & & & Keledang & 14065 & & & & \\
\hline & & & & & & Mempisang & 13923 & & & & \\
\hline
\end{tabular}

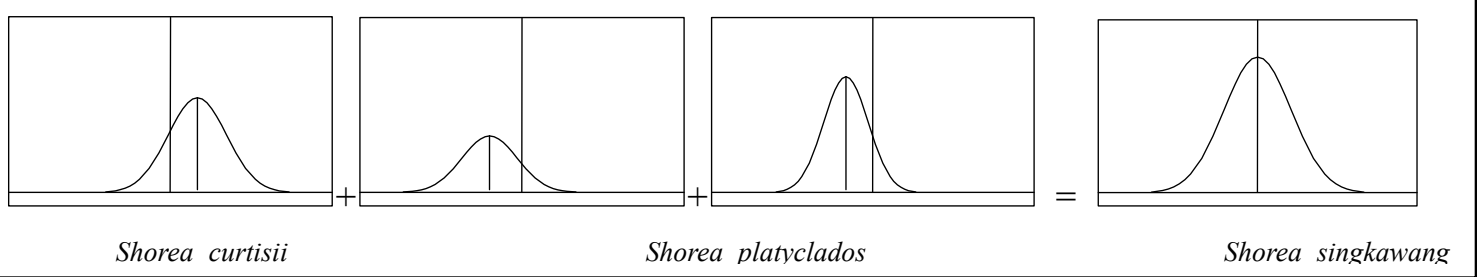

Figure 1. Weighted mean and combined SD of a multispecies Malaysian timber represented in normal distribution structures 